\title{
Ambidexterity in entrepreneurial universities and performance measurement systems. A literature review
}

\author{
Dayanis García-Hurtado ${ }^{1}$ Carlos Devece ${ }^{2}$ Pablo E. Zegarra-Saldaña ${ }^{3}$. \\ Mario Crisanto-Pantoja ${ }^{4}$
}

Accepted: 21 January 2022

(c) The Author(s) 2022

\begin{abstract}
The main purpose of this research is to analyze the exploration and exploitation of knowledge in universities that support innovation and entrepreneurship in their environment. For this, the Performance Measurement Systems (PMS) of the universities management are analyzed as a proxy for the implementation of the strategic vision of the universities. This study is based on a systematic literature review on the subject, supported by the technical possibilities offered by the MAXQDA (The Art of Data Analysis) program. The databases used were the following: Elsevier (Science Direct), Springer, Wiley and Taylor \& Francis. The main findings suggest that organizational ambidexterity, in general, develops unevenly and from different approaches, among which innovation, learning and strategy stand out. However, organizational ambidexterity hardly develops in a university context, where most of the university activities require some knowledge of the technological frontier. Therefore, it is necessary to analyze and understand these two dimensions (exploration and exploitation) and their positive influence on entrepreneurship. In a context where the development of technology and science happens at an ever-increasing speed, a balance between exploration and exploitation is necessary, which should be reflected in the different control mechanisms in academic environments, such as the Performance Measurement Systems (PMS). The analysis of these systems will allow to know the position of the universities in the face of ambidexterity.
\end{abstract}

Keywords Ambidexterity · Innovation · Performance measurement system · Universities · Entrepreneurial

Carlos Devece

cdevece@upvnet.upv.es

1 Department of Organization and Planning, University of Ciego de Ávila, Ciego de Ávila, Cuba

2 Department of Business Organization, Universitat Politècnica de València, Valencia, Spain

3 Universidad Privada Boliviana, Cochabamba, Bolivia

4 Universitat Politècnica de València, Valencia, Spain 


\section{Introduction}

The triple helix model proposed by Etzkowitz and Leydesdorff (1995) is based on the following three axes: industry, university and government. This model rethinks the role of the university in science and technology. In this sense, the university, in collaboration with the industry, establishes mechanisms that promote entrepreneurship in businesses by supporting activities such as business incubators (Nicholls-Nixon et al., 2020). Shane (2004) defines entrepreneurial university as "an important catalyst for the facilitation of academic entrepreneurship, which in turn generates regional economic and social development through the added value created by the identification and exploitation of entrepreneurial opportunities." In response to the dynamism of the environment, entrepreneurial universities become a natural incubator and provide structural support to entrepreneurs to start new companies.

In order to achieve outstanding results in an activity linked to the limits reached in science, it is necessary to balance the exploration and exploitation of knowledge (Burgess et al., 2015). Exploitation entails refinement and extension of existing competencies whereas exploration requires experimentation with new alternatives (March, 1991, p. 85). The organizational ability to combine exploration and exploitation strategies has been named as ambidexterity in the literature (Duncan, 1976).

Recent studies show the need to balance technology transfer (exploitation) and research development (exploration) at the same time. In the context of entrepreneurial universities, the role of ambidexterity and its positive influence on the performance of the organization has been recognized. The literature considers ambidexterity in the university as a balance between research and commercialization activities (Chang et al., 2016) such as collaborative relationships between university and industry (Pangarso et al., 2020; Sengupta \& Ray, 2017). However, from the university point of view, the balance between these two strategies (exploitation vs. exploration) continues to be a topic poorly studied (Centobelli et al., 2019).

The implementation of combined strategies of exploration and exploitation is a crucial challenge for universities (Centobelli et al., 2019). The management of these processes requires, in the first place, the use of control elements which has been developed in other activities but have improved the Management Control System (MCS) of universities (Nisio et al., 2018; Peris-Ortiz et al., 2019). However, MCS should be transferred to a university environment and adapted to their management needs. (Al-Hosaini \& Sofian, 2015; Pietrzak et al., 2015).

In the general approach of MCS, the importance of Performance Measurement Systems (PMS) in strategic implementation is clear. However, in the context of the exploration and exploitation of knowledge in entrepreneurial universities, there is lacking of studies that address the use of PMS. Therefore, the main objective of this article is to evaluate the exploration and exploitation of knowledge in entrepreneurial universities and its relationship with the PMS.

The specific objectives of the study are the following: (1) To evaluate the exploration and exploitation activities used by entrepreneurial universities, (2) To 
evaluate the implementation of PMS for the control of exploitation and exploration in Higher Education Institutions (HEI), and (3) To determine the indicators related to exploration and exploitation activities.

The structure of this article is as follows. The first section presents the theoretical framework. Afterwards, the method followed in the literature review is described. The analysis and results of the literature review are commented in the fourth section. Subsequently, the outcomes related to the theoretical development of the exploration and exploitation strategies are presented. Afterwards, these strategies and the exploration and exploitation activities are analyzed in the HEIs. Finally, this article presents the conclusions extracted from the literature analysis performed.

\section{Theoretical framework}

This section is focused on presenting the necessary background for the current study. First, a brief review on the ambidexterity strategy in universities is presented. Afterwards, the MCS as a management tool for knowledge exploration and exploitation activities is analyzed.

\section{Ambidexterity in universities}

The mission of universities has gone beyond teaching and nowadays has a great variety of objectives. Most of the universities consider the interaction with the environment as one of their main objectives because the development of competencies and knowledge transfer can be achieved through their relationship with public organizations and private companies in the near context (Abramo et al., 2011; Giones, 2019). The goal is to become an entrepreneurial university, a generator and promoter of knowledge that bases its development on innovation and problem solving for the benefit of society and the economic growth. The outcomes of these university-industry (U-I) links is an increase in regional innovations (Parmentola et al., 2020).

The current environment is characterized by continuous innovations, and universities must redefine their strategy in terms of exploration and exploitation to improve their performance in the long term (Benner \& Tushman, 2003). Universities must achieve different objectives in research (exploration) and in the transfer and commercialization of knowledge (exploitation). The organizational ability to combine exploration and exploitation strategies has been termed ambidexterity in the literature. (Duncan, 1976).

However, exploration and exploitation are contradictory and necessary processes (Hiebl, 2015). The literature suggests some ways to solve the existing conflicts between exploration and exploitation. On the one hand, the establishment of alliances: the exploratory efforts of one company contribute to the exploitation capacities of another (Bedford, 2015). Another solution would be for the organization to alternate between periods of exploitation and exploration (Nickerson \& Zenger, 2002; Siggelkow \& Levinthal, 2003). However, universities need to divide their resources between exploration and exploitation at the same time. 
In order to achieve outstanding results in an activity linked to the limits reached in science, it is necessary to balance the exploration and exploitation of knowledge (Burgess et al., 2015). Universities that adopt exploration strategies seek to produce radical changes in knowledge, or at least absorb the knowledge generated without becoming obsolete. These actions will allow them to get the capacity to generate innovations that significantly transform the existing products and processes (Nguyen et al., 2016). Exploration includes aspects captured by terms such as search, variation, risk taking, experimentation, play, flexibility, discovery, innovation (March, 1991).

On the other hand, exploitation refers to the application of knowledge to promote the production of innovations, refine the organization's existing products, and improve its processes. It is conceptualized as refinement, selection, production, efficiency, implementation and execution of existing technologies (March, 1991).

In general, for a company, activities related to exploitation allow increasing the effectiveness of the technical system through routine and successive repetitions, but also by making modifications to established procedures which will increase the outcomes (Bedford, 2015). However, for a university, exploitation means applying its knowledge by collaborating with companies and generating, thanks to the explored knowledge, radical innovations.

\section{MCS for ambidexterity}

According to Bisbe and Otley (2004), the Simons (1991) levers of control is one of the best approaches to analyze the influence of MCS in the processes of exploration and exploitation of knowledge. Simons (1991) argues that the full potential of control is achieved when a dynamic tension is created to maintain a balance between ensuring the achievement of predetermined objectives and allowing the necessary flexibility for innovation and creativity. The framework proposed by Simons (1991, 1995 ) integrates four levers and recognizes three main tensions: (1) unlimited opportunity vs. limited attention, (2) intended vs. emergent strategy, and (3) self-interest vs. desire to contribute (Simons, 1995, p. 153). The framework focuses primarily on the tensions between the organizational need for innovation and the organizational need to achieve pre-established goals, and the resulting tensions created between elements of the formal MCS (Bisbe \& Otley, 2004; Mundy, 2010).

Simons (1991) levers of control proposal are one of the most interesting conceptual frameworks to analyze the influence of MCS on ambidextrous organizations. Research studies have analyzed the effectiveness of MCS by considering their design and use. In this sense, the main findings indicate that the form of use (interactive or diagnostic use) plays a fundamental role (Agostino \& Arnaboldi, 2012; Bedford, 2015).

More recent approaches such as the PMS try to overcome the problems of traditional MCS, which are focused on financial and budgetary control mechanisms (Franco-Santos \& Otley, 2018). PMS developed from planning elements including objectives and performance. They are designed from measurement and reward elements. Measurement elements include the metrics used to operationalize 
performance and the monitoring used to evaluate performance and feedback information. Reward elements are linked to performance, and can be extrinsic (i.e. bonuses) or intrinsic (i.e. social recognition of achievements) ( Franco-santos \& Otley, 2018).

\section{Method}

In order to analyze the abundant literature about the ambidextrous organizations and the implementation of PMS, we have followed a systematic review methodology suggested by (Ridley, 2012; Tranfield et al., 2003). The first phase consists in planning the review. The steps for this phase are the following: (1) to identify the need to outperform a literature review and (2) to develop the review protocol.

It was necessary to perform a preliminary literature review in order to define the scope and evaluate the relevance and size of the literature on the subject. The review protocol implemented includes information on the objective of the study, the research questions, the search strategies, and the design of the data extraction form.

The second phase of the review is the documentary analysis, supported by the technical possibilities offered by the MAXQDA program (Kuckartz \& Rädiker, 2019). Previous studies have used MAXQDA to facilitate the coding of data obtained from interview and secondary sources (Adiloglu \& Besler, 2021; Bausch et al., 2021). In the systematic literature review, MAXQDA has been used as the main tool because it allows step-by-step categorization (Birkel \& Müller, 2021). The MAXQDA's qualitative analysis package contains tools that combine automatic coding of results with manual analytical work that enables paraphrasing and searching for combinations or strings of texts. This phase consists in four steps (Fig. 1).

The identification of the relevant literature was conducted on the following databases of recognized validity: Elsevier (Science Direct), Springer, Wiley, and Taylor $\&$ Francis. These Publishers have recognized prestige in the area of economics and management (Giménez-Toledo \& Tejeda-Artigas, 2015). To identify relevant studies on these databases, a search for scientific articles that used the combined terms of "ambidexterity + innovation" in the period from 2000 to 2020 was performed. Articles from conferences, books, or any other scientific publication different from journal articles were excluded. As it can be seen in Fig. 2, the area that has generated the most articles was Management, with 2,226 articles in the last 20 years.

The preliminary list of articles was built with the articles found on the Management discipline. The analysis of the articles with the MAXQDA tools (automatic coding, lexical searches and word tree) showed different lines of arguments that in many cases do not answer our research questions.

In order to reduce the field to articles related to the subject of this research, we apply other inclusion and exclusion criteria. We focused on the last 15 years, which is also the time span with the most significant increase in articles published on the subject. We identified relevant studies that used the combined terms of "ambidexterity + innovation/ university". Figure 3 shows the results distributed in the different databases, showing a notable increase in the literature that addresses the issue of ambidexterity and performance in organizations. 


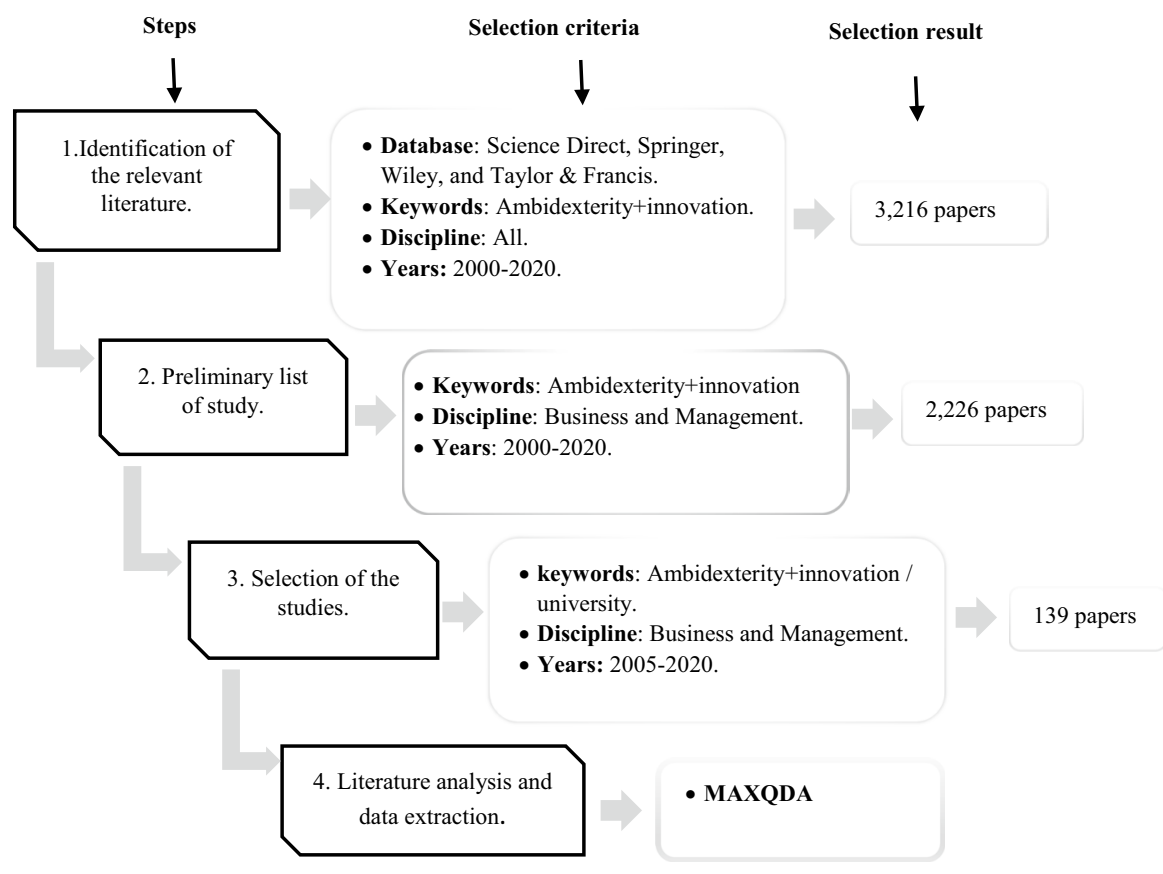

Fig. 1 Bibliographic documentary analysis

\section{Analysis and results}

\section{Ambidexterity in the development of innovations}

In recent decades, the scientific literature dealing with the contradictions between exploitation and exploration and the need to link these two orientations has boomed. Table 1 shows an analysis of the articles published in prestigious journals that are mainly focused on the different modes of ambidexterity and their relationship with innovative performance.

The current environment in which organizations develop, characterized by the need to keep up with competitors by introducing innovations much more frequently, raises the question of which strategy (exploration or exploitation) is better to achieve successful innovative performance. The answer to this question lies on the balance between exploitation and exploration, which implies that organizations have the capacity to pursue and achieve two different types of related objectives in the adaptation to the market, the radical innovation (exploratory) and the incremental innovation (exploitative) (Birkinshaw \& Gupta, 2013; Hiebl, 2015). However, these two approaches (exploration and exploitation) compete for the allocation of resources and require different organizational structures, strategies, contexts and capacities, and can have different impacts on the performance of the organization. In this sense, organizations can develop modes of ambidexterity in different areas such as structure, strategies, knowledge management, 


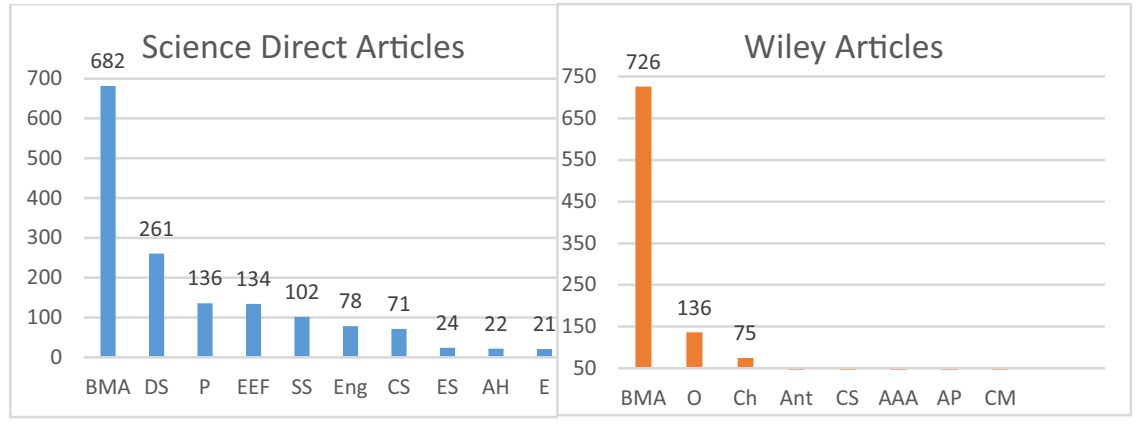

\section{Abreviations:}

BMA: Business, Management and Accounting

Abreviations:

BMA: Business, Management and Accounting; O: Other; Econometrics and Finance; SS: Social Sciences; Eng: Science; AAA: Art \& Applied Arts; AP: Architecture \& Engineering; CS: Computer Science; ES: Environmental Plannin; CM: Communication \& Media studies Science; AH: Arts and Humanities; E: Energy

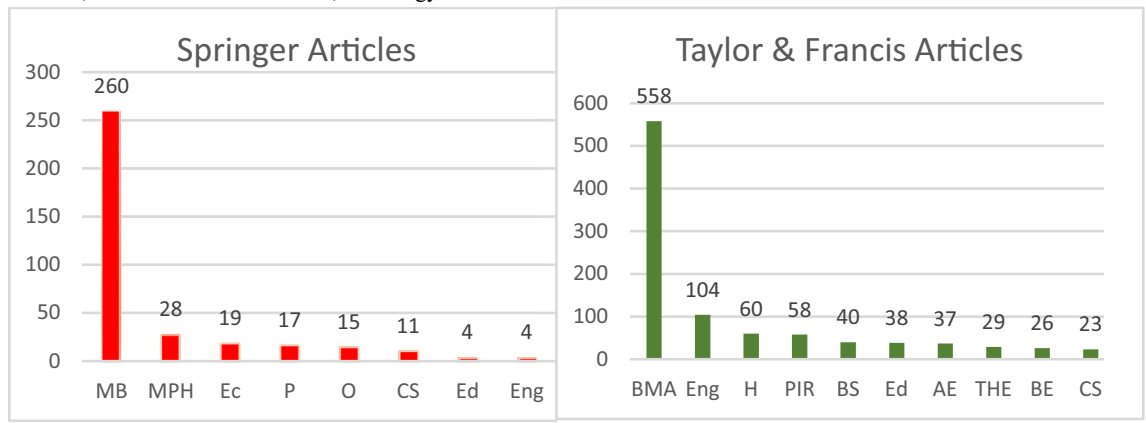

Abreviations:

Abreviations:

BM: Business and Management; MPH: Medicine \& BMA: Business, Management and Accounting; Eng:

Public Health; Ec: Economics; P: Philosophy; O: Others; Engeneering; H: Humanities; PIR: Politics \& CS: Computer Science; Ed: Education; Eng: International Relations; BS: Behavioral Sciences; Engeneering Ed:Education; AE: Area Studies; THE: Tourism, Hospitality and Events; BE: Built Environment; CS: Computer Science

Fig. 2 Distribution of articles with ambidexterity and innovation in the keywords by areas

organizational learning, behavior, innovation, open innovation, and PMS (see Table 1).

\section{Ambidexterity in the context of entrepreneurial universities}

In entrepreneurial universities, the crucial role of ambidexterity and its positive influence on their innovative performance has been widely recognized in both public and private universities (Table 2). Ambidexterity stimulates the development of innovation processes and ensures successful performance (Cabeza-Pulles et al., 2020). However, the importance of balancing exploitation and exploration periods in entrepreneurial universities remains as a poorly researched topic (Centobelli et al., 2019). 


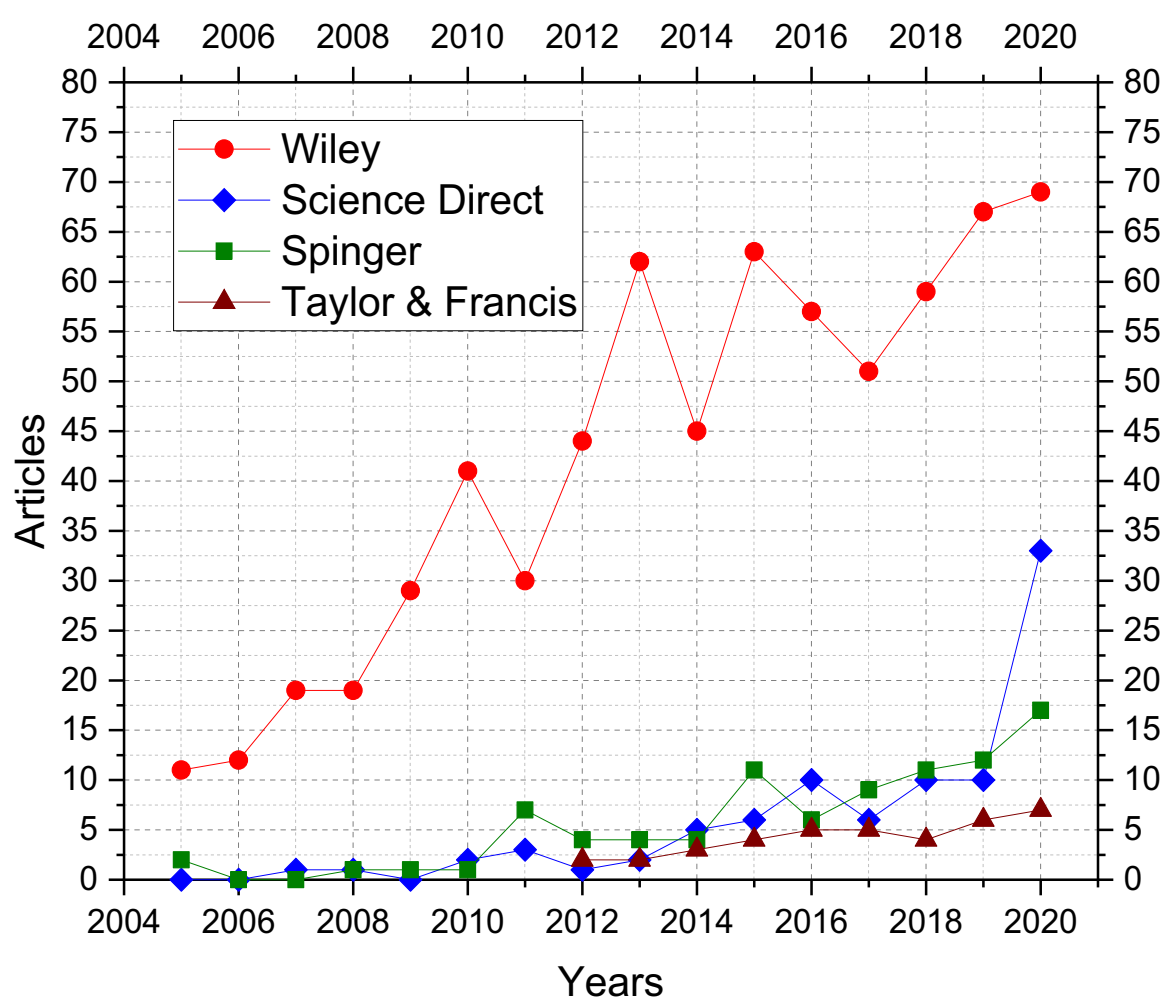

Fig. 3 Articles related to ambidexterity published in the management area

The university has the obligation to satisfy social needs, either as objectives set by the administration or by the market demand. The first one of these needs consists on promoting quality human capital that could contribute to increase the competitiveness and the development of a region (Hsu \& Chen, 2020; Valero \& Van Reenen, 2019). In formation activities, the university can promote entrepreneurship by balancing theory and practice (Blankesteijn et al., 2021).

In addition to the training of professionals and entrepreneurs, universities are an important external source of innovation for companies (Ferreira \& Carayannis, 2019). Innovation support from universities can take different forms of collaboration, including the creation of joint research facilities, research contracts and consulting agreements (Almeida et al., 2019).

In the U-I relationship, a distinction is made between public and private HEIs. The results of the articles that study the public-private relationship in research and technology transfer show that imbalances can occur due to the inconsistency of objectives (Lascaux, 2019). Kivleniece and Quelin (2012) argue that public-private ties are marked by inherent tensions between private profit-oriented goals and public goals. This means that the knowledge generated by collaboration between universities and private companies could be made later available to other 


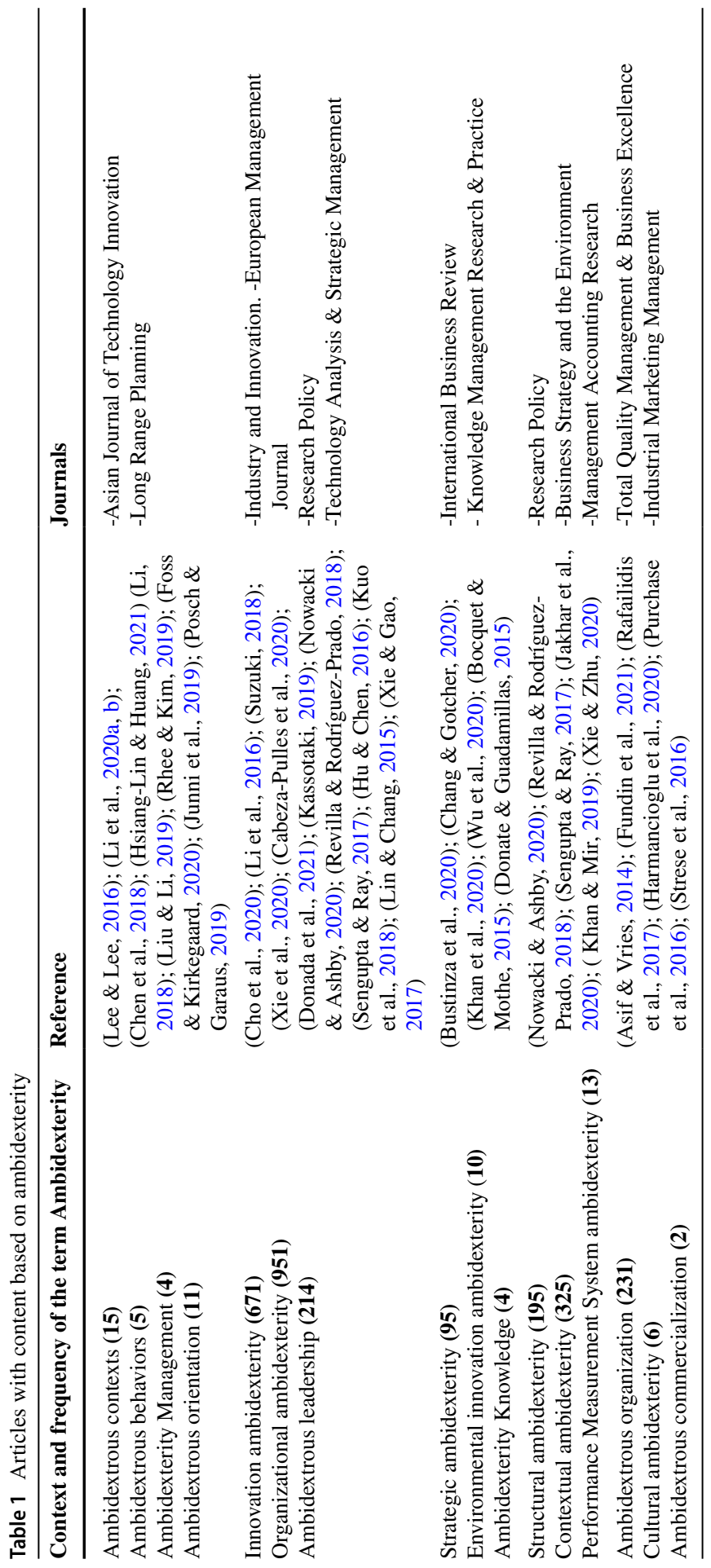




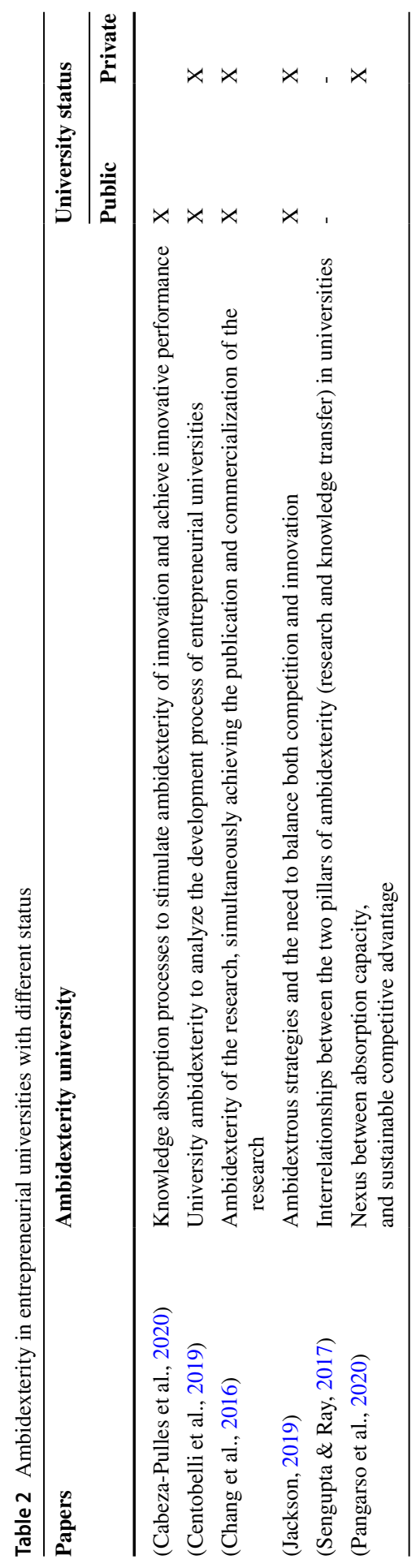


companies through the universities. However, this tension, derived from who has the right to exploit the knowledge generated, is not different from the tensions found in open innovation.

The reputation of universities in the exploration of knowledge can be measured in an international context through global rankings. These rankings could classify the most competitive universities by using an academic and research excellence criterion. In the context of rankings, the radical nature of exploration can be seen in the first-level research indicators, which show the development of scientific production that is published and reaches a high impact.

Incremental innovations are those that produce minor changes in existing activities, products, processes and practices (Damanpour, 2017). In the case of universities, incremental innovation are linked to small upgrades and concrete improvements in existing knowledge, which, although they may be published and disseminated in top-level scientific journals, their impact is smaller than a radical innovation.

Exploration in universities, therefore, is not only limited to the generation of worldwide cutting-edge knowledge. Universities can simply update their knowledge absorbing what was generated by other universities and technology centers. This updated knowledge allows universities to collaborate and support businesses. In this case, universities with fewer resources can act as followers in the generation of knowledge (exploration) without thereby ceasing to be competitive in its technology transfer (exploitation). On these cases, it is important to consider the exploration in universities through the concept of absorption capacity.

Absorption capacity is a critical element in knowledge exploration activities. It is conceptualized as the ability to identify, process, create and use new knowledge. The literature examines different mechanisms that promote the absorption of knowledge in universities, which not only involves internal management but also the relationship with stakeholders from the public and private sectors. On this topic, Lascaux (2019) argues that the absorption capacity in HEIs can be increased through the U-I relationship, which allows identifying the potentialities of the application of new technology in public and private sectors through research projects. This author highlights the importance of strengthening the absorption capacity in the U-I relationship. An initiative to improve the absorption capacity is the informal exchange between the personnel who collaborate with companies and institutions. A second initiative is associated with the establishment of formal mechanisms in structures and activities that foster collaboration. Sharing the acquired knowledge through formal or informal mechanisms increases the potential for the creation of new knowledge and innovative performance (Benitez et al., 2017). This is the reason why the relationships between organizations are particularly important in exploration activities towards the search for innovative performance.

The analysis of the literature shows that there is a focus on the exploitation of knowledge through the commercialization of products and services in the U-I relationships (Robertson et al., 2019). In this sense, the U-I associations emphasize the transformation of knowledge into products and processes that can be commercially exploited. The transfer of technology is achieved through mechanisms such as research contracts, consulting, mobility between researchers, licenses and patents (Da Silva \& Segatto, 2017). 


\section{Performance measurement systems and ambidexterity in entrepreneurial universities}

The university faces serious difficulties to control its processes due to the intangible nature of its exploitation activities and its multiple functions (teaching, research, relationship with the environment). These characteristics of universities and HEIs in general have encouraged their managers to look for management tools. One of these tools is PMS, applied mainly to for-profit organizations, but that can be transferred to universities and adapted to their management needs. However, attempts to adopt PMS can be unsuccessful if the complex and specific nature of entrepreneurial universities are not considered. Table 3 shows a summary extracted from the literature review where the elements of the PMS are exposed by means of using a perspective of exploration and exploitation of knowledge.

Universities pursue multiple and sometimes incompatible objectives that go beyond their traditional role. It is recognized that universities must create new knowledge and apply it through entrepreneurship and innovation (Sengupta \& Ray, 2017). Thus, the development of ambidextrous strategies, based on the management of knowledge in a strategic way, is conditioned by more complex systems that force universities to balance priorities in the creation and transfer of knowledge (Tsen et al., 2020). Table 4 shows the analysis of the literature generated on the topics of U-I collaboration and entrepreneurship initiatives in recent years.

The evidence from the literature analysis reveals that the control element most explicitly or implicitly addressed has been the organizational structure (Apa et al., 2021; Cabeza-Pulles et al., 2020; Fudickar \& Hottenrott, 2018).

Fudickar and Hottenrott (2018) analyze the formal and informal U-I relationships in innovation activities and consider that the exploitation of knowledge through commercialization requires clearly defined objectives to better develop formal interactions. Similarly, Barra and Zotti (2018) suggest that technology transfer offices are a formal intermediate structure between the university and the companies that play an important role in the innovation process. Additionally, Apa et al. (2021) mention that the informal dimension is important, since it has a positive influence on the performance of innovation, even in the absence of formal structures. The results that suggest that formal collaborations that are not accompanied by an informal relationship do not influence innovative performance have important repercussions for the management of the human relations of the U-I collaborative teams.

The reward systems are the second most studied control element in the entrepreneurial university. An incentive mechanism reflects rewards, including salary increases, bonuses or promotions, which are crucial for the success of knowledge transfer and the exploitation of opportunities with companies. Monetary rewards attract more productive researchers and are positively associated with knowledge production. Similarly, Khadhraoui et al. (2016) argue that incentives for successful technology transfer activities can act as a driving force for further innovation in universities.

One of the key components within the control system are the performance indicators. They allow checking if the results of the implementation of the strategy match the objectives (Franceschini et al., 2019). Knowledge exploration indicators 


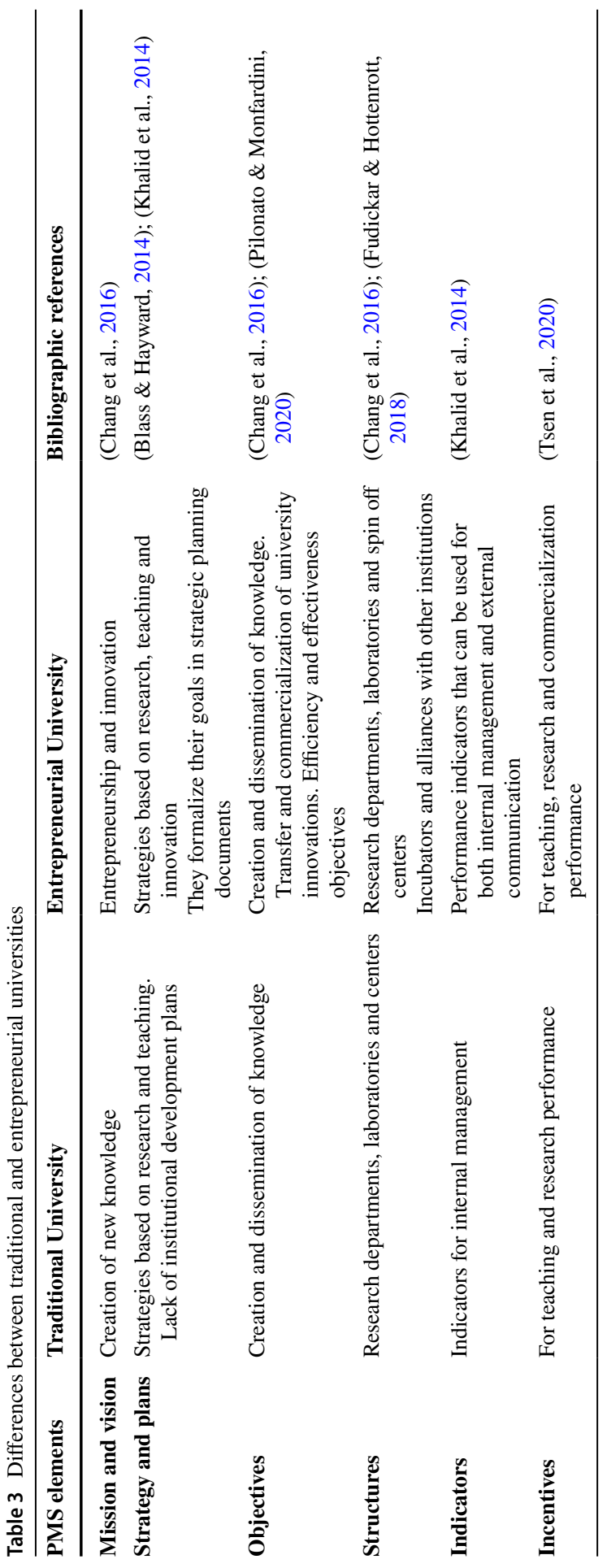




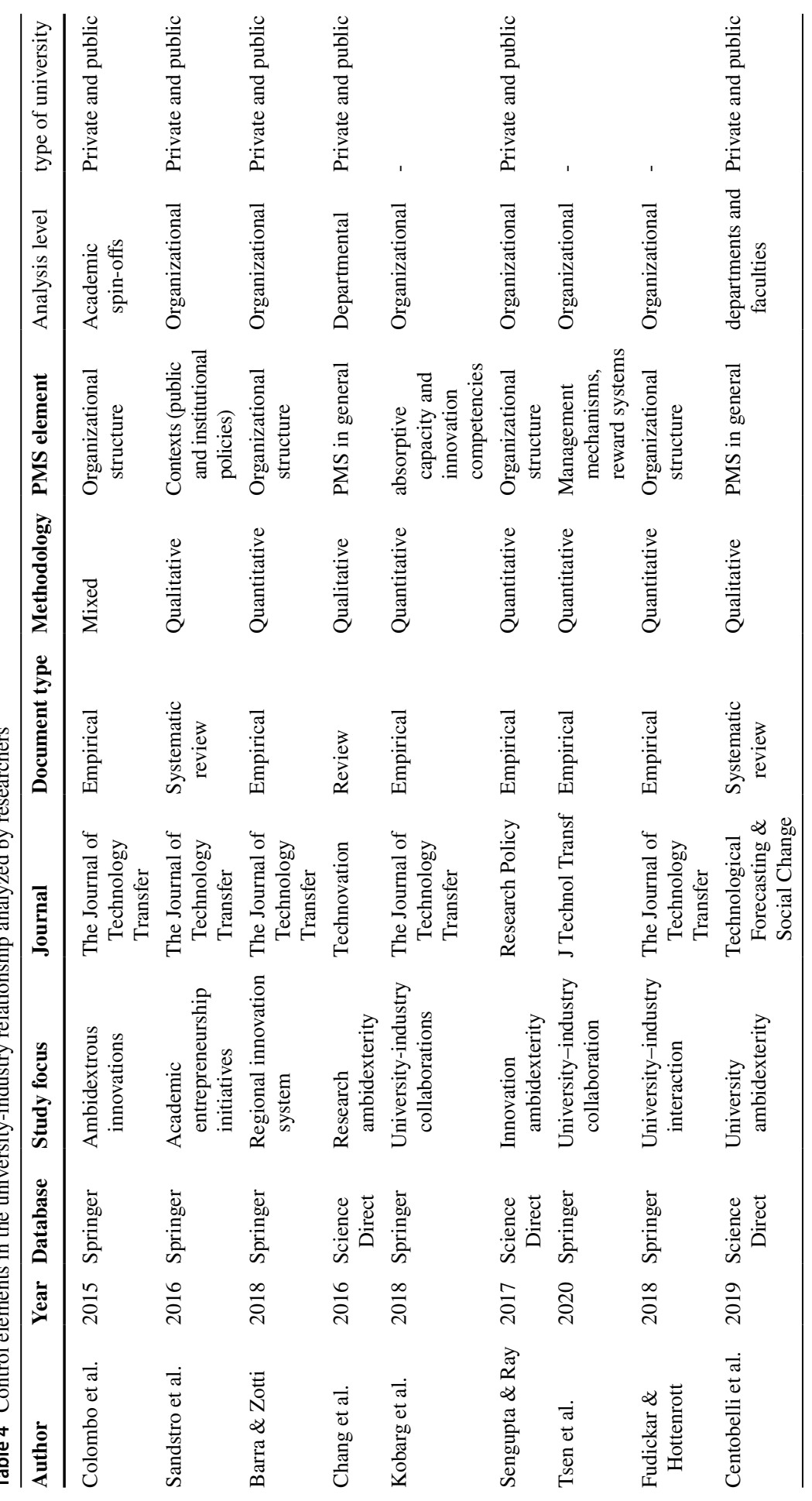




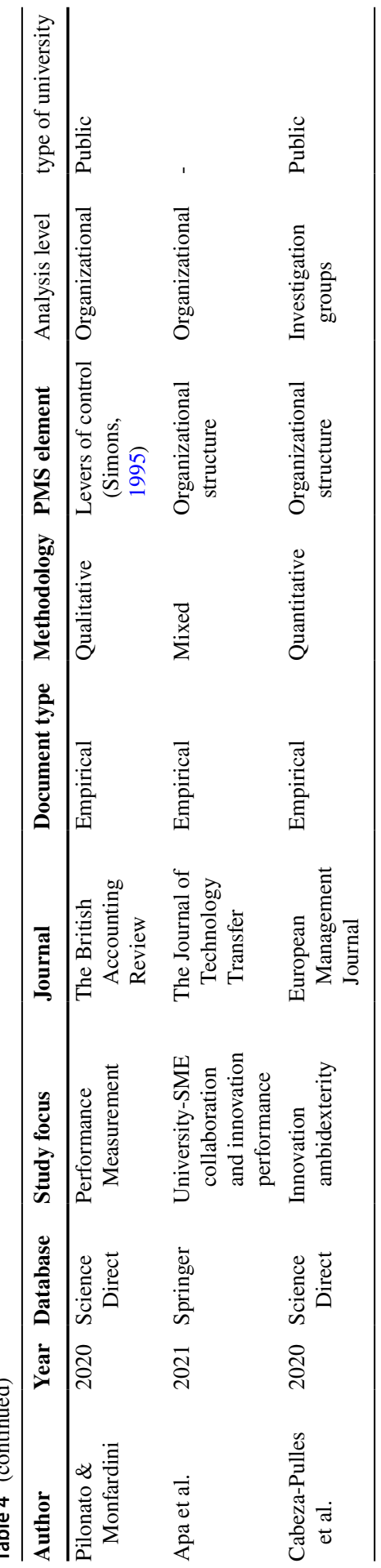


are generally measured in the number of publications and citations in specialized, international, peer reviewed, indexed journals (Amador et al., 2018). This explicit knowledge in the form of scientific publications is usually evaluated according to the impact of the publication. However, the distinction between the creation of knowledge that is simply incremental (linked to a position of follower by scientists in that field), and the knowledge that is a radical innovation (leader of the area of knowledge) is not always made. An interesting indicator to establish the leadership position of the university in a certain field and the type of knowledge it generates are the prestigious awards the university and its researchers have received.

\section{Conclusions}

The dynamics of processes in HEIs have changed in recent years. The new trends position the university as an entrepreneurial organization, as a creator and promoter of knowledge that bases its development on innovation and problem solving for the benefit of society and economic growth. This change of position is given by the speed in the creation of scientific knowledge by society. It is an increasingly complex and specialized knowledge, which updates and progresses much faster. This is the society of knowledge, of scientific knowledge. The fourth sector, constituted by highly qualified and specialized professionals dedicated to creating or at least keeping pace with scientific knowledge in order to apply it, is probably what will define the type of society in the near future. How can this fourth sector be articulated? Which role must play the universities in the knowledge society?

The excessive specialization of knowledge workers and the time necessary for their formation seem to be detrimental to the development of the fourth sector in a completely productive business world. In this context, universities appear as the best positioned organizations to play a central the role in the scientific knowledge creation and absorption if they learn how to balance and coordinate exploration and exploitation activities, which in other words means that they become ambidextrous organizations.

The concept of ambidexterity is very present in the business world. The analysis of the literature indicates the growing need to manage exploration and exploitation as two necessary dimensions in organizations. The term ambidexterity has increased its presence in publications in the last 10 years. Articles related to the words ambidexterity, innovation and performance predominate in business, management and accounting journals.

The results show that ambidexterity is developed in different organizational contexts (Revilla \& Rodríguez-Prado, 2018). Different factors are addressed such as innovation (Cabeza-Pulles et al., 2020; Donada et al., 2021; Pangarso et al., 2020), learning (Duc et al., 2020; Li et al., 2020), management (Li, 2018), business models (Hu \& Chen, 2016), strategies (Bustinza et al., 2020; Wu et al., 2020), structures (Nowacki \& Ashby, 2020), culture (Rafailidis et al., 2017) alliances (Song et al., 2016), processes (Kwak et al., 2019) and PMS (Bedford, 2015). However, only a few of these studies focuses on the university context (Centobelli et al., 2019), where the need to link exploitation and exploration and their positive impact on innovation 
performance has been proven. Ambidexterity in universities has been studied fundamentally from an entrepreneurial approach. In this sense, the university must develop the ability to build capacities and incorporate processes that promote and enhance the activities of exploitation of knowledge, while maintaining its focus on fundamental research (knowledge creation) (Sengupta \& Ray, 2017). In relation to exploration activities, the evidence indicates that these activities are associated with the production of new knowledge that generates an impact on the university community through articles, books, new methodologies or the creation of pioneering technologies (Chang et al., 2016; Sengupta \& Ray, 2017). On the other hand, knowledge exploitation activities are fundamentally based on the commercialization of products and services through U-I relationships (Robertson et al., 2019).

In the context of entrepreneurial universities, a balance between exploration and exploitation and its management through different control mechanisms is necessary. That is why, in recent years, PMS have been implemented in academic organizational structures. The results reveal that PMS are applied mainly for exploitation activities, while activities related to exploration are scarcely analyzed (Centobelli et al., 2019). From the PMS approach proposed by Ferreira and Otley (2009), the control elements that have been addressed in the literature related to organizational ambidexterity were identified. Among the most studied control mechanisms are the organizational structures and reward systems. However, a crucial point in this control process is to identify the correct indicators that properly represent the key performance results and the processes that have led to these results (Franceschini et al., 2019). If we want to measure the exploitation and exploration of knowledge in universities, it is necessary to determine which indicators reflect these two dimensions and which organizational processes should be used in a coordinated way to improve them.

Evidence from the literature review indicates that little attention has been paid to management indicators to establish a balance between exploration and exploitation. The analysis of the research literature on ambidexterity in universities shows that there is not clear distinction between exploration and exploitation in these institutions, and that relevant factors, such as the effectiveness in exploitation of the follower universities, have not been sufficiently analyzed compared to factors dominated by leading universities.

Regarding the traditional role of universities, the formation and teaching activities, there is not a clear distinction, among the indicators usually implemented in universities, between indicators that measure the training of new professionals and the ones used for measuring the knowledge updating of people who have already a professional career. Further, there is no distinction between the indicators for incremental and radical innovative activities in companies collaborating with universities, nor if these companies are at the same time followers or leaders in the industry. All this information is crucial for the management of universities, the selection of the most suitable strategy to follow, and the use of different management tools to achieve the objectives.

Future research should study the performance of universities on both dimensions, exploitation and exploration, with standardized indicators, and link this performance with resource, strategy and incentive systems. Universities play an essential role in 
the knowledge society and medium and small HEIs should understand how to establish their strategy and to employ their limited resources to improve the competitiveness of the industry and society that finance their activity.

Funding Open Access funding provided thanks to the CRUE-CSIC agreement with Springer Nature.

Availability of data and material Data used are public (Papers published in journals included in the databases of Elsevier, Springer, Wiley and Taylor \& Francis).

Code availability Not applicable.

\section{Declarations}

Conflicts of interest Not applicable.

Open Access This article is licensed under a Creative Commons Attribution 4.0 International License, which permits use, sharing, adaptation, distribution and reproduction in any medium or format, as long as you give appropriate credit to the original author(s) and the source, provide a link to the Creative Commons licence, and indicate if changes were made. The images or other third party material in this article are included in the article's Creative Commons licence, unless indicated otherwise in a credit line to the material. If material is not included in the article's Creative Commons licence and your intended use is not permitted by statutory regulation or exceeds the permitted use, you will need to obtain permission directly from the copyright holder. To view a copy of this licence, visit http://creativecommons.org/ licenses/by/4.0/.

\section{References}

Abramo, G., D’Angelo, C., \& Di Costa, F. (2011). University-industry research collaboration: A model to assess university capability. Higher Education, 62(2), 163-181.

Adiloglu, L.-Y., \& Besler, S. (2021). Journal of Air Transport Management Institutional factors influencing business models: The case of Turkish Airlines. Journal of Air Transport Management, 91, 101-989.

Agostino, D., \& Arnaboldi, M. (2012). Design issues in Balanced Scorecards : The " what " and " how" of control. European Management Journal, 30, 327-339.

Al-Hosaini, F., \& Sofian, S. (2015). A Review of Balanced Scorecard Framework in Higher Education Institution (HEIs). International Review of Management and Marketing, 5(1), 26-35.

Almeida, V., Ferreira, J., \& Ferreira, F. (2019). Developing a multi-criteria decision support system for evaluating knowledge transfer by higher education institutions. Knowledge Management Research \& Practice, 17(4), 358-372.

Amador, S. R., Pérez, M. D., López-Huertas, M. J., \& Rodríguez- Font, R. J. (2018). Indicator system for managing science, tecnology and innovation in universities. Scientometrics, 115, 1575-1587.

Apa, R., De Marchi, V., Grandinetti, R., \& Sedita, S. R. (2021). University -SME collaboration and innovation performance the role of informal relationships and absorptive capacity. The Journal of Technology Transfer, 46, 961-988.

Asif, M., \& De Vries, H. J. (2014). Creating ambidexterity through quality management. Total Quality Management \& Business Excellence, 26(11-12), 1226-1241.

Barra, C., \& Zotti, R. (2018). The contribution of university, private and public sector resources to Italian regional innovation system (in)efficiency. The Journal of Technology Transfer, 43(2), 432-457.

Bausch, M., Barmeyer, C., \& Mayrhofer, U. (in press). Facilitating factors in the cross-cultural transfer of management practices: The case of a German multinational in Brazil. International Business Review, (September 2021). 
Bedford, D. S. (2015). Management control systems across different modes of innovation : Implications for firm performance. Management Accounting Research, 28, 12-30.

Benitez, J., Castillo, A., Llorens, J., \& Braojos, J. (2017). IT-enabled knowledge ambidexterity and innovation performance in small U.S. firms: The moderator role of social media capability. Information \& Management, 55(1), 131-143.

Benner, M., \& Tushman, M. L. (2003). Exploitation, exploration, and process management: The productivity dilemma revisited. Academy of Management Review, 28(2), 238-256.

Birkel, H., \& Müller, J. M. (2021). Potentials of industry 4. 0 for supply chain management within the triple bottom line of sustainability - A systematic literature review. Journal of Cleaner Production, $289,125-612$.

Birkinshaw, J., \& Gupta, K. (2013). Clarifying the distinctive contribution of ambidexterity to the field of organization studies. Academy of Management Perspectives, 27(4), 287-298.

Bisbe, J., \& Otley, D. (2004). The effects of the interactive use of management control systems on product innovation. Accounting, Organizations and Society, 29, 709-737.

Blankesteijn, M., Bossink, B., \& van der Sijde, P. (2021). Science-based entrepreneurship education as a means for university-industry technology transfer. International Entrepreneurship and Management Journal, 17(2), 779-808.

Blass, E., \& Hayward, P. (2014). Innovation in higher education; will there be a role for " the academe / university " in 2025 ? The European Journal of Futures Research, 2(41), 1-9.

Bocquet, R., \& Mothe, C. (2015). Can a governance structure foster cluster ambidexterity through knowledge management? An empirical study of two French SME clusters. Knowledge Management Research \& Practice, 13, 329-343.

Burgess, N., Strauss, K., Currie, G., \& Wood, G. (2015). Organizational ambidexterity and the Hybrid Middle Manager: The case of patient safety in UK Hospitals. Human Resource Managemen, 54, 87-109.

Bustinza, O. F., Vendrell-Herrero, F., \& Gomes, E. (2020). Unpacking the effect of strategic ambidexterity on performance. A crosscountry comparison of MMNEs developing product-service innovation. International Business Review, 26(6), 101569.

Cabeza-Pulles, D., Fernandez-Perez, V., \& Roldan-Bravo, M. I. (2020). Internal networking and innovation ambidexterity: The mediating role of knowledge management processes in university research. European Management Journal, 38(3), 450-461.

Centobelli, P., Cerchione, R., \& Esposito, E. (2019). Exploration and exploitation in the development of more entrepreneurial universities : A twisting learning path model of ambidexterity. Technological Forecasting \& Social Change, 141, 172-194.

Chang, K. H., \& Gotcher, D. F. (2020). How and when does co-production facilitate eco-innovation in international buyer-supplier relationships? The role of environmental innovation ambidexterity and institutional pressures. International Business Review, 29(5), 101731.

Chang, Y- C., Yang, P. Y, Martin, B. R., Chi, H- R., \& Tsai-lin, T- F. (2016). Entrepreneurial universities and research ambidexterity : A multilevel analysis. Technovation, 54, 7-21.

Chen, M., Yang, Z., Dou, W., \& Wang, F. (2018). Flying or dying ? Organizational change, customer participation, and innovation ambidexterity in emerging economies. Asia Pacific Journal of Management, 35(1), 97-119.

Cho, M., Bonn, M. A., \& Han, S. J. (2020). Innovation ambidexterity : Balancing exploitation and exploration for startup and established restaurants and impacts upon performance. Industry and Innovation, 27(4), 340-362.

Da Silva, E., \& Segatto, A. P. (2017). Innovation In Universities: Brazilian Academic Research in The Period of 2001-2010. International Journal of Innovation, 5(3), 289-310.

Damanpour, F. (2017). Organizacional Innovation. Oxford Research Encyclopedia of Business and Management, 1-47.

Donada, C., Mothe, C., \& Alegre, J. (2021). Managing skunkworks to achieve ambidexterity: The Robinson Crusoe effect. European Management Journal, 39(2), 214-225.

Donate, M. J., \& Guadamillas, F. (2015). An empirical study on the relationships between knowledge management, knowledge-oriented human resource practices and innovation. Knowledge Management Research \& Practice, 13(2), 134-148.

Duc, L. A., Tho, N. D., Nakandala, D., \& Lan, Y. (2020). Team innovation in retail services: The role of ambidextrous leadership and team learning. Service Business, 14(1), 167-186.

Duncan, R. B. (1976). The ambidextrous organization: Designing dual structures for innovation. The Management of Organization, 1, 167-188. 
Etzkowitz, H., \& Leydesdorff, L. (1995). The Triple Helix - University-Industry-Government Relations: A Laboratory for Knowledge Based Economic Development. EASST Review, 14(1), 14-19.

Ferreira, A., \& Otley, D. (2009). The design and use of performance management systems: An extended framework for analysis. Management Accounting Research, 20(4), 263-282.

Ferreira, J., \& Carayannis, E. G. (2019). University-industry knowledge transfer - unpacking the "black box ": An introduction. Knowledge Management Research \& Practice, 17(4), 353-357.

Foss, N. J., \& Kirkegaard, M. F. (2020). Blended ambidexterity : The copresence of modes of ambidexterity in William Demant Holding. Long Range Planning, 53(6), 102049.

Franceschini, F., Galetto, M., \& Maisano, D. (2019). Theory and Practice of Key Performance Indicators. In Designing Performance Measurement Systems.

Franco-Santos, M., \& Otley, D. (2018). Reviewing and Theorizing the Unintended Consequences of Performance Management Systems. International Journal of Management Review, 20(3), 696-730.

Fudickar, R., \& Hottenrott, H. (2018). Public research and the innovation performance of new technology based firms. The Journal of Technology Transfer, 44(2), 326-358.

Fundin, \& A., Backström, T., Johansson, P. E. (2021). Exploring the emergent quality management paradigm. Total Quality Management, 32(5-6), 476-488.

Giménez-Toledo, E., \& Tejeda-Artigas, C. M. (2015). Process of publication, quality and prestige of scientific education publishers. Educación XX1, 18(1), 17-44.

Giones, F. (2019). University - industry collaborations : An industry perspective. Management Decision, 57(12), 3258-3278.

Harmancioglu, N., Sääksjärvi, M., \& Jan, E. (2020). Cannibalize and combine ? The impact of ambidextrous innovation on organizational outcomes under market competition. Industrial Marketing Management, 85, 44-57.

Hiebl, M. R. W. (2015). Family involvement and organizational ambidexterity in later-generation family businesses A framework for further investigation. Management Decision, 53(5), 1061-1082.

Hsiang-Lin, C., \& Huang, M.-C. (2021). Does dual Embeddedness matter ? Mechanisms and patterns of subsidiary ambidexterity that links a Subsidiary' s dual Embeddedness with its learning strategy. Asia Pacific Journal of Management, 38(4), 1431-1465.

Hsu, B., \& Chen, Y.-M. (2020). Why university matters : The impact of university resources on foreign workers ' human and social capital accumulation. International Entrepreneurship and Management Journal, 17(1), 45-61.

Hu, B., \& Chen, W. (2016). Business model ambidexterity and technological innovation performance : Evidence from China. Technology Analysis \& Strategic Management, 28(5), 583-600.

Jackson, N. C. (2019). ScienceDirect Managing for competency with innovation change in higher education: Examining the pitfalls and pivots of digital transformation. Business Horizons, 62(6), $761-772$.

Jakhar, S. K., Bhattacharya, A., Rathore, H., \& Mangla, S. K. (2020). Stakeholder pressure for sustainability : Can " innovative capabilities " explain the idiosyncratic response in the manufacturing firms ? Business Strategy and the Enviroment, 29(6), 2635-2653.

Junni, P., Chang, Y. Y., \& Sarala, R. (2019). Ambidextrous Orientation and Performance in Corporate Venture Units: A Multilevel Analysis of CV Units in Emerging Market Multinationals. Long Range Planning, 53(6), 101930.

Kassotaki, O. (2019). Explaining ambidextrous leadership in the aerospace and defense organizations. European Management Journal, 37(5), 552-563.

Khadhraoui, M., Plaisent, M., Lakhal, L., \& Prosper, B. (2016). Factors Inhibiting University-Industry technology transfer. Journal of Information Technology \& Economic Devolopment, 7(2), 1-11.

Khalid, S., Knouzi, N., Tanane, O., \& Talbi, M. (2014). Balanced scoreboard, the performance tool in higher education: Establishment of performance indicators. Procedia Social and Behavioral Sciences, 116, 4552-4558.

Khan, S. J., \& Mir, A. A. (2019). Ambidextrous culture, contextual ambidexterity and new product innovations: The role of organizational slack and environmental factors. Business Strategy and the Enviroment, 28(4), 652-663.

Khan, Z., Amankwah-Amoah, J., Kyu, Y., Puthusserry, P., \& Czinkota, M. (2020). Strategic ambidexterity and its performance implications for emerging economies multinationals. International Business Review, 101762.

Kivleniece, I., \& Quelin, B. V. (2012). Creating and capturing value in public-private ties: A private actor's perspective. Academy of Management Review, 37(2), 272-299. 
Kuckartz, U., \& Rädiker, S. (2019). Analyzing qualitative data with MAXQDA. Text, audio, and video. Cham, Switzerland: Springer International Publishing.

Kuo, T., Lim, S. S., \& Sonko, L. K. (2018). Catch-up strategy of latecomer firms in Asia : A case study of innovation ambidexterity in PC industry. Technology Analysis \& Strategic Management, 30(12), 1483-1497.

Kwak, C., Lee, J., \& Lee, H. (2019). Do teams need both hands ? An analysis of team process ambidexterity and the enabling role of information technology. International Journal of Information Management, 51(11), 102038.

Lascaux, A. (2019). Absorptive Capacity , Research Output Sharing , and Research Output Capture in University-Industry Partnerships . Scandinavian Journal of Management, 35(3), 101045.

Lee, Y., \& Lee, J. (2016). Knowledge workers ' ambidexterity : Conceptual separation of competencies and behavioural dispositions. Asian Journal of Technology Innovation, 24(1), 22-40.

Li, C., Liu, Y., Lin, C., \& Ma, H. (2016). Top management team diversity, ambidextrous innovation and the mediating effect of top team decision-making processes. Industry and Innovation, 23(3), 260-275.

Li, R., Fu, L., \& Liu, Z. (2020a). Does openness to innovation matter ? The moderating role of open innovation between organizational ambidexterity and innovation performance. Asian Journal of Technology Innovation, 28(2), 251-271.

Li, S., Ruiqian, J., Seufert, J. H., Wang, X., \& Luo, J. (2020b). Ambidextrous leadership and radical innovative capability: The moderating role of leader support. Creativity and Innovation Management, 29(4), 621-633.

$\mathrm{Li}, \mathrm{X}$. (2018). Is B Yin-Yang balancing superior to ambidexterity as an approach to paradox management ? Asia Pacific Journal of Management, 36(1), 17-32.

Lin, C., \& Chang, C. (2015). A patent-based study of the relationships among technological portfolio, ambidextrous innovation, and firm performance. Technology Analysis \& Strategic Management, 27(10), 1193-1211.

Liu, Y., Li, W., \& Li, Y. (2019). Ambidexterity between low cost strategy and CSR strategy : Contingencies of competition and regulation. Asia Pacific Journal of Management, 37(12), 633-660.

March, J. (1991). Exploration and exploitation in organizational learning. Organization Science, 2(1), 71-89.

Mundy, J. (2010). Creating dynamic tensions through a balanced use of management control systems. Accounting, Organizations and Society, 35(5), 499-523.

Nguyen, B., Yu, X., Melewar, T. C., \& Hemsley-brown, J. (2016). Brand ambidexterity and commitment in higher education: An exploratory study. Journal of Business Research, 69(8), 3105-3112.

Nicholls-Nixon, C. L., Valliere, D., Gedeon, S. A., \& Wise, S. (2020). Entrepreneurial ecosystems and the lifecycle of university business incubators: An integrative case study. International Entrepreneurship and Management Journal, 17, 809-837.

Nickerson, J. A., \& Zenger, T. R. (2002). Being efficiently fickle: A dynamic theory of organizational choice. Organization Science, 13, 547-566.

Nisio, A., De Carolis, R., \& Losurdo, S. (2018). Introducing performance management in universities : The case of a university in Southern Italy. International Journal of Management in Education, 12(2), 132-153.

Nowacki, C., \& Monk, A. H. B (2020). Ambidexterity in government The influence of different types of legitimacy. Research Policy, 49 (1), 103840.

Pangarso, A., Siti, E., Raharjo, K., \& Afrianty, T. W. (2020). Data in brief Data of innovation ambidexterity as a mediator in the absorptive capacity effect on sustainable competitive advantage. Data in Brief, 29, 105200.

Parmentola, A., Ferretti, M., \& Panetti, E. (2020). Exploring the university-industry cooperation in a low innovative region. What differences between low tech and high tech industries ? International Entrepreneurship and Management Journal, 17, 1469-1496.

Peris-Ortiz, M., García-Hurtado, D., \& Devece, C. (2019). Influence of the balanced scorecard on the science and innovation performance of Latin American universities. Knowledge Management Research \& Practice, 4(17), 373-383.

Pietrzak, M., Paliszkiewicz, J., \& Klepacki, B. (2015). The application of the balanced scorecard ( BSC ) in the higher education setting of a Polish university. Online Journal of Applied Knowledge Management, 3(1), 151-164. 
Pilonato, S., \& Monfardini, P. (2020). Performance measurement systems in higher education: how levers of control reveal the ambiguities of reforms. The British Accounting Review, 52(3), 100908.

Posch, A., \& Garaus, C. (2019). Boon or curse ? A contingent view on the relationship between strategic planning and organizational ambidexterity. Long Range Planning, 53(6), 101878.

Purchase, S., Kum, C., \& Olaru, D. (2016). Industrial Marketing Management Paths, events and resource use : New developments in understanding innovation processes. Industrial Marketing Management, 58, 123-136.

Rafailidis, A., Trivellas, P., \& Polychroniou, P. (2017). Total Quality Management \& Business Excellence The mediating role of quality on the relationship between cultural ambidexterity and innovation performance. Total Quality Management \& Business Excellence, 28(9-10), 1134-1148.

Revilla, E., \& Rodríguez-Prado, B. (2018). Bulding ambidexterity through creativity mechanisms : Contextual drivers of innovation success. Research Policy, 47(9), 1611-1625.

Rhee, M., \& Kim, T. (2019). Exploiting old lessons and exploring new ideas : A Confucian approach to exploitation and exploration. Asia Pacific Journal of Management, 36, 773-795.

Ridley, D. (2012). The literature review: A step-by-step guide for students. Sage Publications Ltd.

Robertson, J., McCarthy, I., \& Pitt, L. (2019). Leveraging social capital in university-industry knowledge transfer strategies: A comparative positioning framework. Knowledge Management Research \& Practice, 1(12), 461-472.

Sengupta, A., \& Ray, A. S. (2017). University research and knowledge transfer : A dynamic view of ambidexterity in british universities. Research Policy, 46(5), 881-897.

Shane, S. (2004). Academic Entrepreneurship. Cheltenham, U.K.,: Edward Elgar.

Siggelkow, N., \& Levinthal, D. A. (2003). Temporarily divide to conquer: Centralized, decentralized, and reintegrated organizational approaches to exploration and adaptation. Organization Science, 14, 650-669.

Simons, R. (1991). Strategic orientation and top management attention to control systems. Strategic Management Journal, 12(1), 49-62.

Simons, R. (1995). Levers of control: How managers use innovative control systems to drive strategic renew. Harvard Business School Press.

Song, S. H., Kim, M. J., \& Kang, J. (2016). The effects of ambidextrous alliances on product innovation. Journal of Global Scholars of Marketing Science, 26(1), 14-18.

Strese, S., Meuer, M. W., Flatten, T. C., \& Brettel, M. (2016). Examining cross-functional coopetition as a driver of organizational ambidexterity. Industrial Marketing Management, 57, 40-52.

Suzuki, O. (2018). Uncovering moderators of organisational ambidexterity : Evidence from the pharmaceutical industry. Industry and Innovation, 26(4), 391-418.

Tranfield, D., Denyer, D., \& Smart, P. (2003). Towards a Methodology for Developing EvidenceInformed Management Knowledge by Means of Systematic Review. British Journal of Managemen, 14, 207-222.

Tsen, F. C., Huang, M., \& Chen, D. Z. (2020). Factors of university-industry collaboration afecting university innovation performance. The Journal of Technology Transfer, 45(2), 560-577.

Valero, A., \& Van Reenen, J. (2019). The Economic Impact of Universities : Evidence from Across the Globe. Economic of Education Rewiew, 68, 53-67.

Wu, J., Wood, G., Chen, X., Meyer, M., \& Liu, Z. (2020). Strategic ambidexterity and innovation in Chinese multinational vs . indigenous firms : The role of managerial capability. International Business Review, 29(6), 101652.

Xie, X., \& Gao, Y. (2017). Strategic networks and new product performance: The mediating role of ambidextrous innovation. Technology Analysis \& Strategic Management, 30(7), 811-824.

Xie, X., Gao, Y., Zang, Z., \& Meng, X. (2020). Collaborative ties and ambidextrous innovation : Insights from internal and external knowledge acquisition. Industry and Innovation, 27(3), 285-310.

Xie, X., \& Zhu, Q. (2020). Exploring an innovative pivot : How green training can spur corporate sustainability performance. Business Strategy and the Enviroment, 29(6), 2432-2449.

Publisher's Note Springer Nature remains neutral with regard to jurisdictional claims in published maps and institutional affiliations. 